\title{
A Study on the Construction of Business English Major Based on Knowledge Management
}

\author{
Jinxiang Xue \\ School of Foreign Languages \\ Harbin University of Commerce \\ Harbin, P.R.China 150028
}

\begin{abstract}
Originated from the processes of enterprise management, knowledge management can also be applied to the managerial work in higher education and it is conducive to the construction of Business English Major because it can solve the existing problems such as backward ideas in education, obsolete teaching management model, lack of incentive mechanism, knowledge sharing problem and slow circulation of knowledge that the major faces presently. Having decided the goal-cultivating innovative talents to meet the needs of the society, the methods - establishing knowledge base, talent pool and integrated processing platform, and technologyknowledge management system (KMS) and system platform, this paper puts forward the strategies for applying knowledge management to the management of Business English Major, including network construction of knowledge sharing, establishment of learning team, construction of incentive mechanism, cultivation of knowledge sharing culture and cultivation of innovative talents.
\end{abstract}

Keywords-knowledge management; Business English Major; major construction; KMS; system platform

\section{INTRODUCTION}

Knowledge management refers to the processes of creating value from the intangible assets of an organization, which is a knowledge-based system, and it is an integration of the software engineering processes, organizational improvement, artificial intelligence, human resources management and organizational behaviour ${ }^{[1]}$.

In nature, knowledge management is the objective demand of social development and economic growth in this new era which is thirsty for knowledge. The basic activities of knowledge management consist of knowledge acquisition, consolidation, storage, sharing, application and innovation. The theories and methods of knowledge management have been widely used in enterprises for quite a long time, and it has also been applied to teaching management of schools of various levels in recent years ${ }^{[2]}$.

As a newly-developed major in China, educators and researchers who are involved in the management and research for Business English Major intend to use the

1. Supported by Philosophy and Social Sciences Research Program of Heilongiiang Province: A Study on Ecological Module of Business English Talents Developing in Heilongjiang Province (Grant No.: 15EDB01);

2. Supported by Philosophy and Social Sciences Research Program of Heilongiiang Province: Research on the Feature of Business English "Triadic Reciprocal” Discipline (Grant No.: 16YYD11). relatively advanced theories, methods and technology of knowledge management to construct and develop the Business English Major in order to fulfill the goal of the major - cultivating innovative talents with strong ability who can satisfy the era's needs and stand out in the fierce competition in the talent market in the future ${ }^{[3]}$.

\section{Problems Existing IN THE TEACHING MANAGEMENT OF BUSINESS ENGLISH MAJOR}

\section{A. Backward Ideas on Education}

For a rather long time, the educational concepts which focus on exams and marks in China have nearly penetrated into every field of education and resulted in bad effects like students' incompetence and lack of innovation, and teachers' low teaching quality. However, the deeply-rooted ideas, though they have exerted a negative influence on education, cannot be eliminated due to these traditional ideas on education have been in operation for such a long time. Fortunately, educators in education have realized this problem and put forward a great number of measures to resolve this issue. To improve the teaching quality and training level, and cultivate students' innovative spirit and real ability, universities must clarify the teaching requirements and the goal of curriculum design, teachers should know more and better about how to improve their teaching methods and teaching level, and students should know about the advanced learning strategies required by the time ${ }^{[4]}$. The achievement of this goal requires a better way of management.

Therefore, the advanced way of managementknowledge management should be applied in higher education $^{[5]}$, especially for the business-English majors who will be exposed to numerous tasks which require real ability in real contexts in their future career and life. More specifically, it is important that universities with Business English Major should provide students with courses and training which can facilitate students with real ability rather than textbook knowledge, to make students have innovative consciousness and real abilities like problem-solving ability and reasoning ability.

Knowledge management, in fact, will involve nearly everyone in a university, and it will affect the management processes and policies in all aspects ${ }^{[6]}$. Therefore, to 
effectively support knowledge management in colleges and universities, first of all it is of great importance for school leaders to clearly know and firmly implement knowledge management ${ }^{[7]}$. However, currently, the truth is that many university leaders have not realized it and probably the government should play the most significant role in this matter by issuing relevant policies and rules to solve the problem.

Now that in essence knowledge management is a continuous cycle and a gradual process, it is very difficult to have the implementation effect fully tested in the short term, therefore the university leaders should make it as an indispensable part of the school's long-term plan $^{[8]}$.

\section{B. Obsolete Teaching Management Model}

The traditional teaching management model at schools of various levels in China is the product of the planning economic system in the past, and the implementation of teaching management is usually made in accordance with the policies and administrative regulations issued by the government and other authorities. This type of management model has centralized, unified, and rule-based characteristics, which played a very important role in the history of the development of education in China. However, in the course of teaching management, it gradually produced a number of shortcomings and disadvantages, such as students being slow, lack of inefficient, etc.

The out-of-date management model and old system in China could not adapt to the rapidly expanding scale of enrollment at university level nowadays, and as a result, it hinders the goal of endowing talents with innovative spirit and practical ability. More specifically, the old policies and managerial mechanism can not effectively promote the enthusiasm of teachers and students to develop and make a difference ${ }^{[9]}$. These problems have become the bottleneck to improve teaching quality of higher education.

\section{Lack of Incentive Mechanism}

Traditional management model in education hinders effective knowledge innovation within an organization, because the organization members may be afraid that knowledge innovation may result in losing their status and power in the organization because of its relatively high investment and low profit ${ }^{[10]}$. Although the knowledge innovation will improve the overall level of knowledge of an organization, it is not necessarily conducive to an individual.

In universities, the task of research and innovation of knowledge is relevant to the needs of all the teaching staff and therefore it seems that teachers will be happy to handle them. However, the real situation is that due to research in teaching requires a lot of efforts and hard work and a rather long time, therefore, when the teachers can not get the corresponding compensation for their investment, the research job will lag behind and the spread of knowledge and innovation will become an effort in vain ${ }^{[11]}$. For a long time, due to the lack of an effective incentive, and the ignorance of the significance of the development of organizational knowledge, universities have been facing enormous challenges both in academics and in real trivial work, which actually has a very influence on teaching quality and the development of students.

\section{Knowledge Sharing Problem}

Knowledge sharing is the effective way to maximize the value of knowledge, but there are many obstacles in its processes. Knowledge can be divided into tacit knowledge and explicit knowledge. As tacit knowledge often exists in the minds of the people, it is a kind of so-called intangible wealth, and it is associated with the individuals' thoughts and behavior. However, the organizations like colleges and universities are under most circumstances featured by a Pyramid-shaped hierarchy structure, which covers multiple levels of management, resulting in slow information transmission, lack of adaptability and flexibility, information loss or distortion ${ }^{[12]}$. Eventually, it has hindered the realization of knowledge sharing in colleges and universities.

The knowledge sharing barrier among teachers in universities is very noticeable because teachers are usually worried that sharing knowledge will lead to losing their skills and making them lose their advantages in some certain areas. From a psychological point of view, the owner of knowledge has not only the needs for success, but also reputation and power, and the hidden knowledge or experience on special expertise can satisfy this kind of desire.

\section{E. Slow Circulation of Knowledge}

The processes of the circulation of tacit knowledge and explicit knowledge are beneficial to the improvement of the quantity and quality of knowledge. However, there are some difficulties in the processes. With the development of the Internet, it is very convenient for people to search for tacit knowledge, but there will be tens of thousands of results, which will negatively influence the efficiency of knowledge searching because most of them are not combed and selected. This is the difficulty of learning tacit knowledge.

In an organization, the members do not intend to spend time in managing the searched knowledge. It is partly due to this job is time-consuming, partly because the knowledge may be out of date very soon and partly because this job may reveal the business secrets of this organization. As for explicit knowledge, due to it is more difficult than tacit knowledge, it needs an even longer time for someone to acquire it, and in the process of turning explicit knowledge into tacit one ${ }^{[13]}$, some important contents may be omitted. That is the difficulty of accumulating explicit knowledge in organizations, including universities.

\section{KEY FACTORS OF KNOWLEDGE MANAGEMENT FOR BUSINESS ENGLISH MAJOR}

\section{A. The goal}

As the teaching management and talents cultivating department, the Business English Major is in charge of the teaching affairs concerning all the teachers and students in this major. The Business English Major also shoulders the responsibility for the basic construction of teaching service, 
undertakes all the relevant teaching elements such as planning, coordination and guidance, and provides a variety of statistics for data collection and analyses and decisionmaking for the school and the government.

Therefore, the goal of the Business English Major, which is based on the full investigation of the actual situations and the demand of the society, should be to promote the development of the major, strengthen the sharing of information and resources, and establish the teaching management system to cultivate qualified talents who can serve the society successfully in the future ${ }^{[14]}$. This task requires advanced management methods and technology. It is suggested that through the integrated use of information technology and resources, the Business English Major should utilize comprehensive teaching techniques like the websites and multimedia to learn and use advanced teaching management methods such as knowledge management to improve teaching quality and teaching management in a scientific way. In particular, it is of great significance for universities to use the effective technology platforms to improve the teaching management work.

\section{B. Methods}

In the construction of the teaching management system, the first problem is business process reengineering (BPR $)^{[15]}$.

Firstly, it is suggested to analyze and research the status of teaching management, and the relevant theories of knowledge management to optimize the design of management processes, management and related research institutes.

Secondly, it is required to learn from advanced management experiences, on the basis of comparative analyses to optimize the teaching management processes, design and develop educational websites, and constantly improve the system function in the processes, with the combination of theory and practice at the same time.

Finally, it is necessary to further standardize the teaching management processes based on effective information, scientific research data, objective analyses and optimization design on the websites to better the functions of the knowledge management-based teaching management system.

To realize knowledge management, first of all knowledge management model should be established and generalized, which include knowledge resources, information technology, organizational structure, culture and other aspects which are related to knowledge. Knowledge management system (KMS), in the narrow sense, refers to the use of information technology to connect people with knowledge ${ }^{[16]}$. The implementation of knowledge management system needs the support of equipment and facilities of the school and campus network environment, which includes three parts: knowledge base, talent pool and integrated processing platform.

\section{THE TECHNOLOGY}

With the development of information technology, knowledge management has been greatly upgraded both in depth and breadth in the new era. Although information technology is just a part of the processes of knowledge management, it is the main tool for the realization of knowledge management. Therefore, it can be said that knowledge sharing is inseparable from the support of information technology ${ }^{[17]}$. Therefore, from a technical point of view, knowledge management is to pass right knowledge at the right time to the right people with the help of technology.

\section{A. $K M S$}

The logical structure of KMS consists of five parts: knowledge acquisition, knowledge discovery, knowledge sharing, knowledge learning, knowledge innovation ${ }^{[18]}$.

1) Knowledge Acquisition: Knowledge acquisition, which is based on Agent technology, database technology and humanity methods, collects data, information and knowledge in an organization. Thanks to the merits of autonomy, Agent learning and adaptation of the model, it is intelligent enough to help users to complete the search and access to work on a network of knowledge in a short time, and to provide the resource base for the subsequent knowledge acquisition phases.

2) Knowledge Discovery: Knowledge discovery refers to the process of identifying the potential and effective knowledge from the data or information. The effective way of the realization of knowledge includes the concept tree ascension, genetic algorithm, neural network, rough set and evidence theory. Knowledge discovery makes it possible to turn information into knowledge, and achieve knowledge innovation.

3) Knowledge Sharing: Knowledge sharing is an important part of realizing knowledge externalization and integration, which needs not only a speedy knowledge spreading network, but also an open, equal, and friendly network environment. The net-based groupware technology can provide the way of knowledge sharing, and through the intelligent collection of logic knowledge cluster, build the visible knowledge visualization map, thus guiding users to capture the required knowledge to improve individual and organizational collaboration efficiency.

4) Knowledge Learning: As a learning system, an organization can be divided into two parts: learning orientation and learning aids. Knowledge visualization map and the core of knowledge chain belong to learning orientation, and the factors such as learning testing methods belong to learning aids. Knowledge learning is an important method of knowledge socialization and internalization, which is also known as the most effective way for innovation.

5) Knowledge Innovation: The key to obtain and maintain competitive advantages lies in the effective knowledge innovation. The main technology for knowledge innovation is the Web technology, for it can provide personalized service, and customize a friendly knowledge interface. Web-based knowledge innovation of individuals 
and organizations can be stored and shared by the Web technology, so as to form a spiral pattern of knowledge innovation.

\section{B. System Platform}

Under the guidance of the ideas and methods of website construction, taking the framework of knowledge management as the foundation, the teaching management system for Business English Major can be classified into five platforms in terms of functions: information releasing platform, transaction processing platform, resource platform, data platform and service platform ${ }^{[19]}$.

1) Information Releasing Platform: Information releasing platform is mainly to announce information to the school and all levels of teaching management units, and display the latest situations of teaching and teaching management. It features timeliness and includes different items such as news, information, and notice. This platform makes the communication between schools smooth, enables the school to have a more comprehensive grasp of the effect of the school work, helps teachers and students to exchange information, cultivates a good teaching and research atmosphere, and improves the quality of classroom teaching.

2) Transaction Processing Platform: Transaction processing is an important work in the operation of teaching, which plays a necessary role in the co-ordination and arrangements of the teaching elements such as teachers, students, curriculum, classrooms and so on and so forth. It pays great attention to the accuracy of the data collected and selected. The stable operation of the transaction processing platform is the key to guaranteeing the daily teaching order, including all the teaching operation functions: course selection, results entry, query results, evaluation of teaching, teachers leave, examinations, and administration.

3) Resource Platform: Resource platform is the core of the system. After classification, integration and connection, knowledge forms a plurality of high quality resources, to provide adequate net source to promote students' autonomous learning and cultivate talents' abilities. Resource platform includes a large number of outstanding achievements in the teaching quality construction project and teaching reform, such as the construction of the teaching achievement award, specialty, teaching syllabus, curriculum, teaching quality, bilingual courses, international exchange, the innovative experimental program for undergraduates, research, teaching practice, experimental teaching demonstration center, teacher resources, and postgraduate students data.

4) Data Platform: Data platform aims to provide teachers and students of the Business English Major and other departments and offices with detailed and multidimensional data and information, which includes plan and summary, teaching conference, questionnaire, and data disclosure. Among them, the data disclosure system is the implementation of the policy "to establish the basic teaching data detection system, collect all kinds of basic information and data, get statistics and analyze basic status of university teaching and the changing trend, gradually publicize the data of teaching quality and teaching reform to the society" issued by the Ministry of Education of China[20]. Through the processes of data acquisition, management and disclosure, the platform can also provide a powerful function which covers teaching, information, summary and analysis.

5) Service Platform: The service platform mainly provides academic teaching management and teaching implementation at all levels, including: organization, rules and regulations, download, standardized management, and network application.

Generally speaking, these five platforms, connecting with each other, enhancing mutually, reflecting the conditions of the teaching management, are conducive to reflecting the teaching situations, the dynamic development of schools, colleges and universities, and standardizing management through self diagnosis and scientific decision. The five horizontal platforms link the vertical processes of the undergraduate teaching management for Business English Major, and jointly promote the knowledge management as the key idea supported by information technology to improve teaching and managing quality.

\section{THE KNOWLEdge MANAGEMENT STRATEgIES FOR BUSINESS ENGLISH MAJOR}

University teaching management is fundamentally the management of knowledge, and it is the inevitable choice of colleges and universities. Knowledge management philosophy provides a scientific basis for the improvement of the core competitiveness of colleges and universities. The three elements of knowledge management are the people, knowledge and technology. The establishment of teaching management system based on knowledge management is the technical support for higher schools. As a new major in China, the development of the Business English Major will be a long way. In order to develop smoothly and healthily, the major should attach great importance to the following points ${ }^{[21]}$.

\section{A. Network Construction of Knowledge Sharing}

The knowledge management-based teaching management system is the important support for campus network environment. From viewpoints of knowledge sharing and safety, using VPN technology is the inevitable choice of realizing knowledge management.

Using the public network to connect remote sites or users, branch offices, and teachers' homes, it can break out of knowledge security considerations of IP access control, improve resource utilization, realize the openness and safety of remote teaching, autonomous and cooperative unification, and data communication security end to end. VPN as a new network technology, provides a safe, efficient, flexible and economic network, and solves the problems faced by the Business English Major at all the universities in China. 


\section{B. Establishment of Learning Team}

Through the establishment of team cooperation, it is beneficial to constructing basic organization for teaching, deepening teaching reform, and promoting the sustainable development of the construction of teaching team, teaching research, teaching experience exchange, and the transformation of knowledge. The teaching team aims to achieve a common goal set by interdependent groups of teachers, which is an innovation team that can establish selflearning mechanism. Therefore, the teaching features the mechanism "work to learn, learn to work".

In order to give full play to teachers' creativity, learning should be free and there should be no "self defense" in this aspect. Therefore, in this process, it is also beneficial to teachers' concept, behavior, methods, ways of thinking, knowledge structure, teaching skills and psychology.

\section{Construction of Incentive Mechanism}

Knowledge innovation, as the core part of knowledge managements, colleges and universities should take effective measures to establish a people-oriented incentive mechanism to fully arouse the teachers' and students' awareness of knowledge innovation. In order to meet the needs for talents, universities should constantly improve the incentive mechanism and regulation system, and promote the reform of talent training model timely.

Further, universities should promote autonomous learning and creative teaching to give full play to students' and teachers' innovative potential, to ensure the sustainable development of the effective implementation of the program and the cultivation of innovative talents, to establish and perfect the management and implementation of the program, such as providing effective construction and management of experimental teaching demonstration center, specialized construction, curriculum, teachers and teaching team quality projects, to encourage teachers to participate actively in the cultivation of innovative talents, and to carry out the reform and the practical model of cultivating innovative talents.

\section{Cultivation of Knowledge Sharing Culture}

As in modern organizations, one of the key elements leading to success is cooperation, hence having a good spirit of cooperation has become the indicator of a healthy organizational culture.

Knowledge sharing spirit, in some way, is also a spirit of cooperation and it reflects the corporate culture in an organization. If there is a lack of the spirit of cooperation in a certain organization, it will be very hard for the team to complete a task successfully. This means that it is the knowledge sharing spirit rather than competent individuals that decides whether this organization can achieve its goal or not and it determines the strength and level of the organization. Therefore, culture is the premise and basis of organizational behaviour.

\section{E. Cultivation of Innovative Talents}

Reasonable knowledge structure is the source of cultivating the creativity of college students ${ }^{[22]}$. More specifically, it is through the integration of disciplines that universities can give students a better environment to cultivate their creativity.

Due to the knowledge structure of reserves and students basic knowledge disciplines should be enhanced and extended to a certain degree to achieve the goal, many researchers and experts point out that in order to cultivate innovative talents, schools must make necessary efforts in the integration of the disciplines of knowledge. With the development of the society, the future market needs more innovative talents, and interdisciplinary education can meet the needs and knowledge management correspondingly has become a key factor in this continuous and ongoing process.

\section{CONClusion}

The knowledge management theory originates in the process of enterprise management. Both enterprise management and teaching management have the objective requirements of management efficiency and profit. And this belief makes it possible to borrow the concept of knowledge management from the enterprise management processes. The implementation of teaching management based on knowledge management for Business English Major at undergraduate level in colleges and universities in China can be expected to improve the quality of education and teaching, and benefit teachers and students from all aspects ${ }^{[23]}$.

Although the enterprise management and teaching management have some features in common, they are in different areas and as a result, it requires a long-term exploration to effectively transplant knowledge management from enterprise management to teaching management. With the continuous development of the theory and technology of knowledge management, its application in colleges and universities will be better and more reasonable, and it is hoped that more studies on this issue could be conducted by educators and researchers who are involved in the development of the Business English Major in China in the future.

\section{REFERENCES}

[1] APQC International Benchmarking Clearinghouse. Knowledge Management: Consortium Benchmarking Study Final Report[R]. American Productivity and Quality Center, 1996.

[2] Liu Shengquan. The knowledge management in educational field: A study on knowledge management for teachers[J]. Electrified Education Studies. 2004(6):10-15, 20. (in Chinese)

[3] Xue Jinxiang. A study on the construction of curriculum of Business English Major from the perspective of Ecology[J]. Heilongjiang Higher Education Research, 2013(2):163-165. (in Chinese)

[4] Higher Education Department of the Ministry of Education, P.R.C. An introduction to the majors at undergraduate level of higher schools (2012)[M]. Beijing: Higher Education Press, 2012. (in Chinese)

[5] D.H.Hargreaves.The Knowledge-creating company. British Journal of Educational studies[J]. 1999, 47 (2): 122-144. 
[6] Benjamin Loh, Ai-Chee Tang, Thomas Menkhoff, Yue-Wah Chay, Hans-Dieter Evers. Applying knowledge management in university research[M]. Singapore: Singapore Press, 2003.

[7] Zhang Xuan. Study on college teachers' development from the perspective of knowledge management [J]. Journal of the Chinese Society Education, 2015(S2): 371-372. (in Chinese)

[8] Richard W. Work-based Learning and Quality Assurance in Higher Education[J].Assessment \& Evaluation in Higher Education, 1994, (3): 247.

[9] Yu Yihong. Knowledge management and competivity of higher schools[J]. Research and Development Management, 2002, 14 (2): 14. (in Chinese)

[10] Rowley J. From learning organization to knowledge management entrepreneur [J], Journal of Knowledge Management, 2000, (1): 7-15.

[11] Ikujiro Nonaka. The knowledge-creating company[J].Harvard Business Review, 1991, (11/12).

[12] Bassi L J. Harnessing the Power of Intellectual Capital[J]. Training \& Development,1997, (12):25-30.

[13] Spiegler I. Technology and knowledge: bridging a 'generating' gap [J]. Information \& management, 2003,40 (6): 533-539.

[14] Wang Lifei. Repositioning the discipline and academic research of business foreign languages[J]. China Foreign Languages, 2012 (3):4. (in Chinese)

[15] Sandra Jones. Employee Rights, Employee Responsibilities and Knowledge Sharing in Intelligent Organization[J]. Employee Responsibilities and Rights Journal, 2002 (2): 69-78.

[16] Davenport T H, Delong D W \& Beers M C. Successful Knowledge Management Projects[J].Sloan Management Review, 1998, (2):43-57.

[17] Davenport T H, Prusak L. Working knowledge: how organization manage what they know[M].Boston: Harvard Business School Press, 1998.

[18] Zhang Jianhua, Liu Zhongying. The issue of knowledge management system model and the countermeasures and analysis[J]. Intelligence Academics.2004, 23 (1): 73-77. (in Chinese)

[19] Chai Ying. Undergraduate teaching management research based on knowledge management[D]. Beijing Jiaotong University, 2011. (in Chinese)

[20] Ministry of Education, P.R.C. The ideas on teaching quality and teaching reform project for undergraduates in higher schools issued by the Ministry of Education, P.R.C. (Higher Education, 2007, No. 1.) (in Chinese)

[21] The teaching requirements for undergraduates of higher schools[J]. Higher Education Press, 2009. (in Chinese)

[22] Chen Zhunmin, Wang Lifei. Developing National Curriculum for BA Program in Business English of China [J]. China Foreign Languages, 2009(4): 4-11. (in Chinese)

[23] Xue Jinxiang. A Study on the construction of curriculum of Business English Major from the Perspective of Ecology [J]. Heilongiang Higher Education Research, 2013(2): 163-165. (in Chinese) 